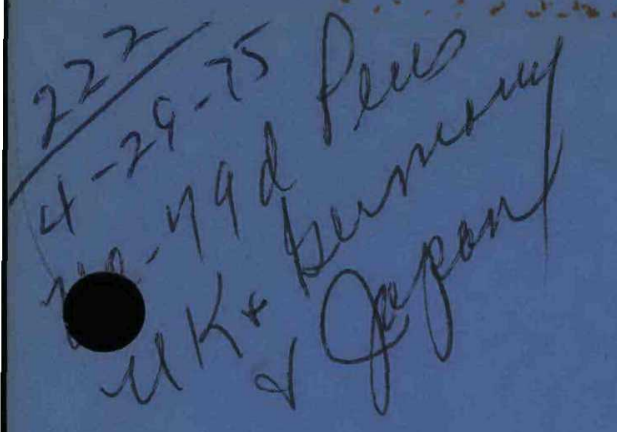

HEDL-TME 75-26

UC-79d

A USERS' MANUAL

FOR COMPUTER CODE RIBD-II

A FISSION PRODUCT INVENTORY CODE

HANFORD ENGINEERING DEVELOPMENT LABORATORY

P.O. Box 1970 Richland, WA 99352 Operated by Westinghouse Hanford Company A Subsidiary of Westinghouse Electric Corporation

Prepared for the U.S. Atomic Energy Commission

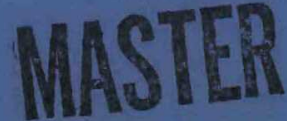
Division of Reactor Research and Development under Contract No. AT(45-1)-2170 


\section{DISCLAIMER}

This report was prepared as an account of work sponsored by an agency of the United States Government. Neither the United States Government nor any agency Thereof, nor any of their employees, makes any warranty, express or implied, or assumes any legal liability or responsibility for the accuracy, completeness, or usefulness of any information, apparatus, product, or process disclosed, or represents that its use would not infringe privately owned rights. Reference herein to any specific commercial product, process, or service by trade name, trademark, manufacturer, or otherwise does not necessarily constitute or imply its endorsement, recommendation, or favoring by the United States Government or any agency thereof. The views and opinions of authors expressed herein do not necessarily state or reflect those of the United States Government or any agency thereof. 


\section{DISCLAIMER}

Portions of this document may be illegible in electronic image products. Images are produced from the best available original document. 


\section{NOTICE}

This report was prepared as an account of work sponsored by the United States Government. Neither the United States nor the United States Atomic Energy Commis. sion, nor any of their employees, nor any of their contractors, subcontractors, or their employees, makes any warranty, express or implied, or assumes any legal liability or responsibility for the accuracy, completeness or usefulness of any information, ap. paratus, product or process disclosed, or represents that its use would not infringe privately owned rights.

\section{Printed in the United States of America Available from \\ National Technical Information Service}

U.S. Department of Commerce 5285 Port Royal Road

Springfield, Virginia 22161

Price: Printed Copy $\$ 4.00$; Microfiche $\$ 2.25$ 


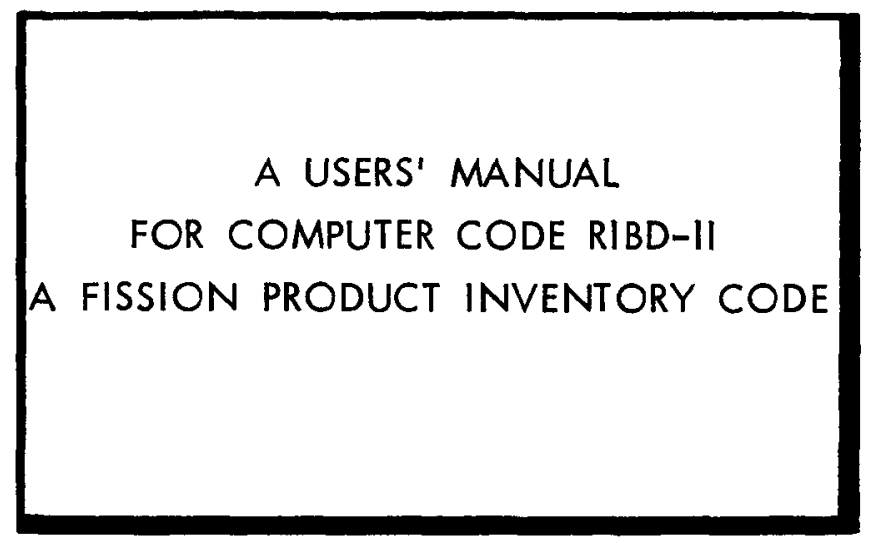

\section{R. Marr}

January 1975

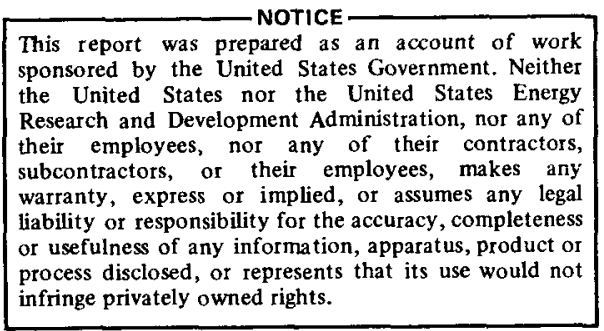

\section{Hanford Engineering Development Laboratory}

Operated by the

Westinghouse

Hanford Company
A Subsidary of

Westinghouse Electric

Corporation for the United States

Atomic Energy Commission

Contract No AT/45-1-2170 
-

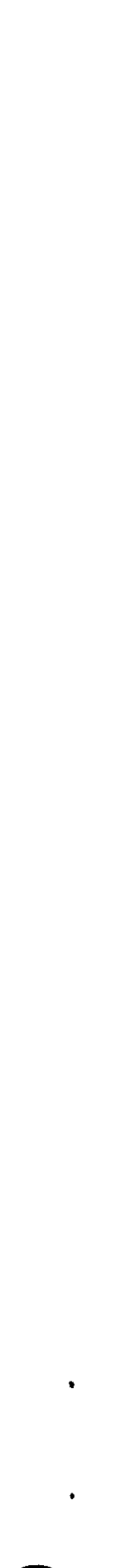

• 
HEDL-TME 75-26

UC 79d

\title{
A USERS' MANUAL FOR COMPUTER CODE RIBD-II, A FISSION PRODUCT INVENTORY CODE
}

\author{
D. R. Marr
}

\begin{abstract}
$\underline{A B S T R A C T}$
The computer code RIBD-II is used to calculate inventories, activities, decay powers, and energy releases for the fission products generated in a fuel irradiation. Changes from the earlier RIBD code are: the expansion to include up to 850 fission product isotopes, input in the user-oriented NAMELIST format, and run-time choice of fuels from an extensively enlarged library of nuclear data. The library that is included in the code package contains yield data for 818 fission product isotopes for each of fourteen different fissionable isotopes, together with fission product transmutation cross sections for fast and thermal systems. Calculational algorithms are little changed from those in RIBD.
\end{abstract}


• 


\section{TABLE OF CONTENTS}

Page No.

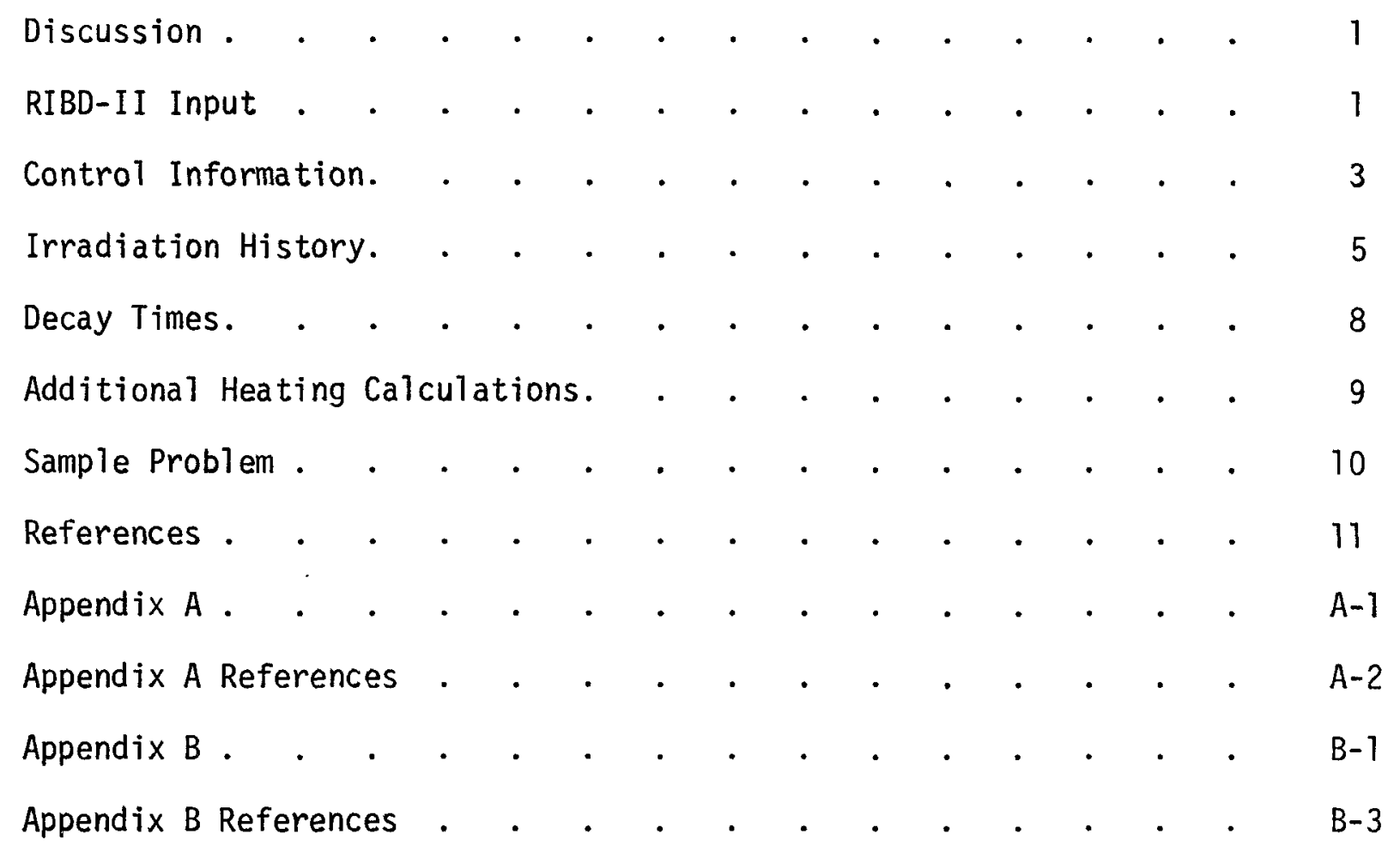




\section{DISCUSSION}

The computer code RIBD ${ }^{(1)}$ is used to calculate the fission product activity, power, and energy release from irradiated fuel by the summation method. Individual isotopic inventories, activities, powers, and energy releases are also generated.

Although suitable for many applications, RIBD, as originally distributed with a 450 isotope library, was found to underpredict the decay power at short cooling times. A 770 isotope library incorporating many short-lived isotopes, was used in a study of the Fast Test Reactor (FTR) decay heat ${ }^{(2)}$ that was a significant improvement over earlier calculations using the 450 isotope $1 i$ brary ${ }^{(3)}$. ENDF/B Version 4 contains nuclear data for over 800 fission product isotopes. In order to access these larger libraries, the RIBD code was enlarged to handle up to 850 isotopes, 96 mass chains, 42 elements, 36 isotopes per element and 12 isotopes per mass chain.

The RIBD library was also changed to a binary format that allows the user to select from fourteen sets of yield data and two sets of cross sections. Overload of library data items with card input is possible for any run. An extensive library has been generated employing the latest available nuclear data from ENDF/B Version 4. It is described in Appendix A.

A few changes in the calculational algorithm have been made since its description in Reference 1. These changes, which improve the numeric performance for certain cases, are detailed in Appendix B.

\section{RIBD-II INPUT}

A complete case of RIBD-II input consists of a title card followed by a single block of NAMELIST input. The input block name is INPUT. NAMELIST is a generally available feature of the FORTRAN coding language. For details of its use, consult a FORTRAN manual.

In NAMELIST input, each input quantity is identified by a unique name. This provides a free field format in which the input quantities may be in any order. Also, position upon the card is unimportant (with the exception that column one cannot be used). All input information is retained in RIBD-II, so succeeding cases need input for only the changed items. 
A complete list of the unique input names together with a description of the input quantity is contained in the following sections along with a sample case input. The RIBD-II output is fully self-explanatory and is not shown here. 


\section{CONTROL INFORMATION}

Input Variable Name

OUTPUT
Units

$-$

NOPE

LIBRY

NULIBE
Notes

OPTIONAL INPUT. A single integer designating the output quantities desired. Output wi11 be for each isotope and element as well as for the total.

Integer

0 Activities, concentrations (default).

1 Activities, concentrations, powers.

2 Powers only.

3 Energy releases between decay points.

4 Powers, energy releases.

5 Complete print.

OPTIONAL INPUT. An integer one suppresses detailed isotopic output; only summaries are printed. An integer zero (default) allows full isotopic detail.

OPTIONAL INPUT. A nonzero integer causes a full printout of the $1 i-$ brary. Valid only for first case in a multicase run.

OPTIONAL INPUT. A nonzero integer causes the current library to be written. In conjunction with the 
CONTROL INFORMATION (cont'd.)

Input Variable Name

\author{
Units
}

Notes

library overload feature (see

Appendix $A$ ), this allows updated

libraries to be saved. 


\section{IRRADIATION HISTORY}

Input Variable

Name

EXPOSE

YIELDS

RATIO

BURNUP

FLUX

SIGMA
Units

MW, days

Notes

REQUIRED INPUT. Exposure history in (power, time) couples. Up to 425 couples each representing a step of power are allowed including any steps of zero power.

REQUIRED INPUT. Two integers designating which two of the fourteen available yields (fuels) should be used for this run. See Appendix A for a description of the fuels available in the library. YIELDS may not be changed in subsequent change cases in a single run.

REQUIRED INPUT. Initial ratio of the fission rate in the second fuel to that in the first fuel.

Two of these three associated quantities are REQUIRED INPUT. BURNUP is the quantity denoted as $T$ in Reference 1. It describes the relative burnout of the two selected fuels for the first time step in the following way

$$
F_{1}=F_{0} e^{-T}
$$


Input Variable Name
Units

where:

$F_{0}$ is the fraction of the fission rate in the first fuel at time zero.

$F_{1}$ is the fraction of the fission rate in the first fuel at the end of the first power step.

The loss in fission rate of the first fuel is compensated by an appropriate increase in the fission rate of the second fuel in order to keep the power constant for the duration of the time step. It may then be shown that

$$
T=\log _{e}\left(\frac{1+\text { RATIO }_{1}}{1+\text { RATIO }_{0}}\right) \text {. }
$$

Alternatively, $T$ may be defined by

$$
T=\text { FLUX } \cdot \text { SIGMA } \cdot \operatorname{EXPOSE~(2)~}
$$

where EXPOSE (2) = exposure time for the first operating step (input, under EXPOSE, see above), and FLUX is the first fuel burnout flux. The value FLUX will also be used in the fission product transmutations for the first time step. In succeeding time steps, the flux will be scaled proportionally to the power. 


\section{IRRADIATION HISTORY (cont'd.)}

Input Variable

Name
Units

SIGMAT

ENF
MeV per fission

\section{Notes}

SIGMA is the differential burnout cross section of the first fuel relative to that of the second (i.e., SIGMA $=\sigma_{1}-\sigma_{2}=$ burnout cross section of first fuel minus the burnout cross section of second fuel).

RIBD-II will calculate the omitted input quantity using the above expression. If all three are entered, a consistent value for FLUX will be calculated and used instead of the input quantity.

OPTIONAL INPUT. The integer one (1) specifies that thermal transmutation cross sections are to be used in this run. Zero (0) specifies cross sections averaged over a fast reactor spectrum. SIGMAT may not be changed in subsequent change cases in this run. Zero is the default value.

OPTIONAL INPUT. Energy released per fission. Used to convert power to fission rate. Default value is 200 MeV per fission. 


\section{DECAY TIMES}

Input Variable Name

DT IMES

DTMULT
Units seconds (unless DTMULT is also entered)
Notes

REQUIRED INPUT. Nonzero decay times at which output is desired, in ascending order. RIBD-II always provides shutdown information in addition to these. From 1 to 850 times may be specified.

OPTIONAL INPUT. DTMULT is used to convert other decay time units to seconds. The decay times above are multiplied by this quantity, if entered, prior to the decay calculation. 


\section{ADDITIONAL HEATING CALCULATIONS}

Input Variable Name

CON

Units

gram/MWD

$\operatorname{mi} 11 j-k$

milli seconds

PNLIFE
Notes

OPTIONAL INPUT. Conversion rate of $\mathrm{U}^{238}$ to $\mathrm{Pu}^{239}$ via the process of neutron capture in $\mathrm{U}^{238}$ and subse-quent beta decay in $\mathrm{U}^{239}$ and $\mathrm{Np}^{239}$. RIBD-II uses this information to calculate the beta and gamma decay powers for these isotopes. Default value is zero and no $\mathrm{U}^{239}-\mathrm{Np}^{239}$ decay is calculated.

DELTAK
OPTIONAL INPUTS. If DELTAK is nonzero, scram transient heating rates will be calculated. DELTAK is the control insertion causing the scram; PNLIFE is the prompt neutron mean lifetime. Delayed neutron data for $U^{235}$ fission is used; therefore, this calculation is meaningful only for thermal reactors with $U^{235}$ fuel. 


\section{SAMPLE PROBLEM}

Suppose we wish to calculate the activity for decay times from 7 to $30^{8}$ seconds of the fission product from the mixed oxide fuel of a fast breeder reactor in which initially $90 \%$ of the fissions occur in $\mathrm{Pu}^{239}$ and $10 \%$ occur in $U^{238}$. Other specifications:

- Conversion rate of $0.5 \mathrm{gm}$ of $U^{238}$ per MWD

- No scram transient calculation

- Relative burnup of .001418

- Flux $=7.3 \times 10^{15} \mathrm{n} / \mathrm{cm}^{2}-\mathrm{sec}$

- 3 cycles of operation ( 1 cycle $=102$ days up, with 34 days outage)

- $100 \mathrm{MW}$.

A suitable card input would then be the following:

SAMPLE PROBLEM TITLE CARD

\$INPUT

$\mathrm{CON}=0.5$, BURNUP $=0.001418$, FLUX $=7.3 \mathrm{E} 15$, RATIO $=0.1111111$,

$E N F=213.5, Y$ YIELDS $=7,4$,

$\operatorname{EXPOSE}(1)=100,102,0,34,100,102,0,34,100,102$,

$\operatorname{DTIMES}(1)=1,10,100,1000,1 . E 4,1 . E 5,1 . E 6,1 . E 7,1 . E 8$,

\$END. 


\section{REFERENCES}

1) R. 0. Gumprecht, "Mathematical Basis of Computer Code RIBD," DUN-4136, June 1968.

2) D. R. Marr and W. L. Bunch, "FTR Fission Product Decay Heat," HEDL-TME 71-27, February 1971.

3) W. L. Bunch and L. D. O'De17, "Fission Product Inventory and Decay Heat Associated With FTR Fue1," BNWL-961, February 1969. 


\section{APPENDIX A \\ RIBD LIBRARY}

A 818 isotope library* is available for use with RIBD-II. It contains yield data for fourteen fission reaction combinations of fuel and incident neutron energy. Ten of these were processed from the fission product data in ENDF/B Version 4. The other items of nuclear data were also processed from ENDF. The fourteen reactions together with the identifying integer entered in the input data as the quantity YIELDS are as follows:

\begin{tabular}{clc} 
Yields & & \\
\hline 1 & $U^{235}$ thermal & ENDF/B-IV \\
2 & $U^{235}$ fast & $"$ \\
3 & $U^{235} 14 \mathrm{MeV}$ & $"$ \\
4 & $U^{238}$ fast & $"$ \\
5 & $U^{238} 14 \mathrm{MeV}$ & $"$ \\
6 & $\mathrm{Pu}^{239}$ thermal & $"$ \\
7 & $\mathrm{Pu}^{239}$ fast & $"$ \\
8 & $\mathrm{Pu}^{241}$ thermal & $"$ \\
9 & $\mathrm{U}^{233}$ thermal & $"$ \\
10 & $\mathrm{Th}^{232}$ fast & $"$ \\
11 & $\mathrm{U}^{238}$ fast & Weaver (A1) \\
12 & $\mathrm{Pu}^{239}$ fast & Anderson (A2) \\
13 & $\mathrm{U}^{235}$ thermal & Weaver \\
14 & $\mathrm{U}^{235}$ 14 MeV & Weaver
\end{tabular}

\section{LIBRARY OVERLOAD}

Any information from the library may be overloaded in the NAMELIST input for the first case. Input variables are:

Variable

MASS (I)

ATNO (I)
Definition

Mass number.

Atomic number.

* This library, compiled by R. E. Schenter of HEDL, will be published in May, and will be entitled "Data Library from ENDF/B-IV for RIBD-II, A Fission Product Inventory Code." 


\section{LIBRARY OVERLOAD (cont'd.)}

Varjable

HALF (I)

$Y(I, J)$

SIG (I)

SIGT (I)

$\operatorname{BRCP}(I)$

$\operatorname{BRD}(\mathrm{I})$
Definition

Half life, days.

Yields in percent, $J$ is the integer associated with a particular set of data (YIELDS).

Capture cross section (fast) in barns.

Capture cross sections (thermal) in barns.

Capture branching ratio - fraction resulting in an isomeric state.

Decay branching ratio - fraction resulting in an isomeric state. (For an isomeric nuclide, it is the fraction which skip the isomeric transition.)

EBETA (I) Mean beta energy in MeV per disintegration.

EGAMMA (I) Mean gamma energy in MeV released per disintegration.

CHMSYM (I) Three-character symbol for nuclide identification such as CO*. Printed in RIBD output.

STATE (I) $=1$ means isomeric state

$=2$ means ground state.

For the appropriate index, I, to use, it is necessary to obtain a library listing (section CONTROL INFORMATION, page 3 ).

\section{References}

A1) L. E. Weaver, P. O. Strom, and P. A. Killeen, "Estimated Total Chain and Independent Fission Yields for Several Neutron Induced Fission Processes," USNRDL-TR-633, U.S. Naval Radiological Defense Laboratory, March 1963.

A2) C. A. Anderson, Jr., "Fission Product Yields From Fast (Approx. I MeV) Neutron Fission of $239 \mathrm{pu}, "$ LA-3383, LASL, December 1965. 


\section{APPENDIX B}

\section{CALCULATIONAL ALGORITHM}

The calculational algorithms used in RIBD-II are unchanged from those developed by Gumprecht and orally reported in Reference B1. They differ slightly from those documented in Reference B2 and primarily represent improvements that avoid numerical troubles sometimes encountered for very short irradiations.

The remainder of this appendix details those differences so that a user with Reference B2 may have a more accurate representation of the algorithms used in RIBD-II.

In Reference B2, two alternate solutions for the isotopic inventory are developed. They are identified as Equations (2) and (3) and are reproduced below.

$$
\begin{aligned}
& I=I_{0} e^{-L_{i}^{\theta}}+P Y_{2}\left(1-e^{-L_{i}^{\theta}}\right) /\left(L_{i}\right)+P_{I} O\left(Y_{1}-Y_{2}\right)\left(e^{-T}-e^{-L_{i}^{\theta}}\right) /\left(L_{i}-X\right) \\
& +\sum_{n=1}^{\infty}\left((-1)^{n-1} F_{n}\left(L_{i} \theta\right) /\left(L_{i} n\right) \cdot \sum_{a 11 j} Y_{j i} D^{n-1}\left(A_{j}\right)\right)
\end{aligned}
$$

where

$$
F_{n}\left(L_{i} \theta\right)=1-e^{-L_{j} \theta} \sum_{n}^{\infty}\left(L_{i} \theta\right)^{m} /(m !) .
$$

$I=$ concentration of nuclide $i$.

$I_{0}=$ concentration of nuclide $i$ at the beginning of this time interval.

$P=$ gross fission rate for this time interval. The fission rate in the first fuel during the time interval is given by $P_{1}(t)=$ $P_{1}^{0} e^{-X t}$ and that for the second fuel is $P_{2}(t)=$ $P-P_{1}(t)=P-P_{1}^{0} e^{-X t} . P_{1}^{0}$ is the fission rate of the first fuel at the beginning of the time interval.

$X=T / \theta$. 
CALCULATIONAL ALGORITHM (cont'd.)

$T=$ exponent applicable to the final fission rate of the first species for this time interval (input parameter).

$\theta=$ length of time, in days, for this time interval.

$I=$ concentration of nuclide, $i$.

$L_{i}=$ loss factor for nuclide, $i \equiv \phi \sigma_{a i}+\lambda_{i}$.

$\sigma_{a i}=$ absorption cross section of nuclide, $i$.

$\lambda_{i}=$ decay constant of nuclide, $i$.

$\phi=X / \sigma$ where the input parameter $\sigma$ is the differential burnout cross section of the two fuels (burnout cross section of the first fuel minus burnout cross section of the second).

$Y_{1}=$ fission yield (as a fraction) of nuclide, $i$, from first species fission.

$Y_{2}=$ fission yield from second species fissions.

$A_{j}=$ concentration of direct ancestor, $j$, of nuclide, $i$.

$Y_{j i}=$ yield operator on path from ancestor $j$ to nuclide, $i$. These factors are developed by multiplying the $\lambda$ of the ancestor (if in the same chain) by the appropriate branching ratio, or the group $\phi \sigma_{a j}$ by $i$ ts appropriate branching ratio if an $n, \gamma$ ancestor is involved.

$D^{n}\left(A_{j}\right)=$ the nth derivative of the concentration of ancestor, $j$, at time $\theta$.

$$
I=I_{0} e^{-L_{i}^{\theta}}+P Y_{2}\left(1-e^{-L_{i}^{\theta}}\right) /\left(L_{i}\right)+P_{i}^{0}\left(Y_{1}-Y_{2}\right)\left(e^{-T}-e^{-L_{i}^{\theta}}\right) /\left(L_{i}-X\right)
$$

$+\sum_{n=1}^{\infty}\left(\left(-L_{j}\right)^{n-1} \cdot \sum_{a 11 j} Y_{j i} D^{-n}\left(A_{j}\right)\right)$

where $D^{-n}\left(A_{j}\right)$ is the nth integral of the concentration of ancestor, $j$, from 0 to $t$ evaluated at $t=\theta$. 


\section{CALCULATIONAL ALGORITHM (cont'd.)}

In RIBD-II, Equation (2) is used when the loss factor $L_{i} \theta$ is greater than 4, otherwise Equation (3) is used.

The series summations over $n$ indicated in Equations (2) and (3) and modified Equation (2), not shown, are terminated after any term added is less than $2 \times 10^{-9}$ of the sum after addition. Up to 20 terms are used, If Equation (2) is being used and convergence cannot be achieved when $L_{i} \theta<4.5$, use of Equation (3) will be attempted before a diagnostic is printed.

During shutdown periods, Equation (4), reproduced below, is used to calculate the inventory.

$$
\begin{aligned}
& I=\sum_{n=1}^{i} c_{n, i} e^{-\lambda n^{\theta}} \\
& \text { and } c_{n, i}=\sum_{j} Y_{j i} c_{n, j} /\left(\lambda_{j}-\lambda_{n}\right)
\end{aligned}
$$

where summation over $j$ refers to the three possible direct ancestors; $\gamma_{j i}$ is the yield operator from ancestor $j$ to nuclide $i$; and $c_{n, j}$ is the nth series coefficient of direct ancestor $j$.

Also, $c_{i, i}=I_{0}-\sum_{n=1}^{i-1} c_{n, i}$

$I_{0}=$ initial concentration of the ith member of the chain. Should the case arise where $\left|\lambda_{n} \theta-\lambda_{i} \theta\right|<.01$, the following alternative form for the nth term in the sum is used.

$$
c_{n, i} e^{-\lambda n_{n} \theta} \sum_{n=1}^{5}(-1)^{m+1} \frac{\left(\lambda_{i} \theta \lambda_{n} \theta\right)^{m}}{m !}
$$

and the $C_{n, i}$ component is excluded from the computation of $C_{i, j}$ before multiplication by $e^{-\lambda} i^{\theta}$. 


\section{References}

B1) R. 0. Gumprecht, "Computer Code RIBD," Trans. ANS, Vo1. 12, No. 1, p. $141,1969$.

B2) R. 0. Gumprecht, "Mathematical Basis of Computer Code RIBD," DUN-4136, June 1968. 
Externa 1

No. of

Copies

204

UC-79 Basic List

18 UC-79d Physics

Interna]

No. of

Copies

AG Fremling

RM Poteat

FFTF-P0

1 RL Ferguson

Westinghouse Hanford Company

28

RA Bennett

RL Boroughs

RO Budd

WL Bunch (2)

JF Fletcher

JW Hagan

JP Hale

WW Litt]e

DR Marr (2)

HC Martin

RP Omberg

RE Peterson

RE Schenter

$F$ Schmittroth

DR Simpson

RJ Slember

DD Stepnewski

AE Waltar

JT Ward

Central Records and Files

Publications Services 